\title{
A Revolver Inlet for Elemental Analyzer
}

\author{
Toshiro SAINo*, Jota KANDA* and Toshiro YAMADA** \\ *The Ocean Research Institute, University of Tokyo, Nakano, Tokyo 164 \\ **The Research Institute for Information and Knowledge, Kanagawa University, \\ Rokkakubashi, Yokohama 221
}

In environmental sciences, the measurements of particulate organic carbon (POC) and particulate organic nitrogen (PON) have routinely been conducted by using an elemental analyzer. POC and PON are defined as organic carbon and nitrogen in particulate materials that are retained on non-combustible filters made of glass fiber, quartz fiber or silver membrane. For the measurements, the particulate materials are combusted on such non-combustible filters.

With conventional analytical procedures, an unreasonably high $\mathrm{N} / \mathrm{C}$ ratio is occasionally experienced most likely due to air contamination. A major part of such contamination is being suspected to stem from air that would be entrapped in the filters and could not be purged out by 2 min purging of helium (carrier gas) recommended in the regular procedure. We report here a simple device, which we name "the revolver inlet", specifically designed to remove the air entrapped in glass fiber filters. A quartz sample tube to be used together with the revolver inlet is also described.

\section{Revolver Inlet and Sample Tube}

Figure 1 illustrates schematics of the revolver inlet. It comprises of inner and outer disks. The former has one single and the latter two cylinders. O-rings are appropriately placed between the two disks for sealing purpose. The disks are pressed firmly to each other with a spring coil at the center of the disks. The revolver inlet is fitted to the combustion tube of an elemental analyzer with another $\mathrm{O}$-ring.

Throughout the whole operation helium gas is continuously discharged from the helium inlet of the revolver. Glass fiber filter with sample is first folded and then placed in a quartz sample tube as depicted in Fig. 2. The tube loaded with the glass fiber filter sample is inserted into the cylinder at evacuation position. With a cap screwed on tightly, the sample is evacuated to vacuum by a rotary pump. After keeping vacuum for $1 \mathrm{~min}$, the outer disk is revolved to the purging position. The cap at the end must be removed

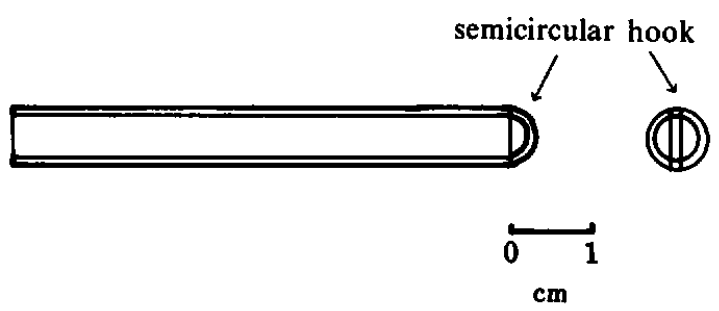

Fig. 2 Sample tube.

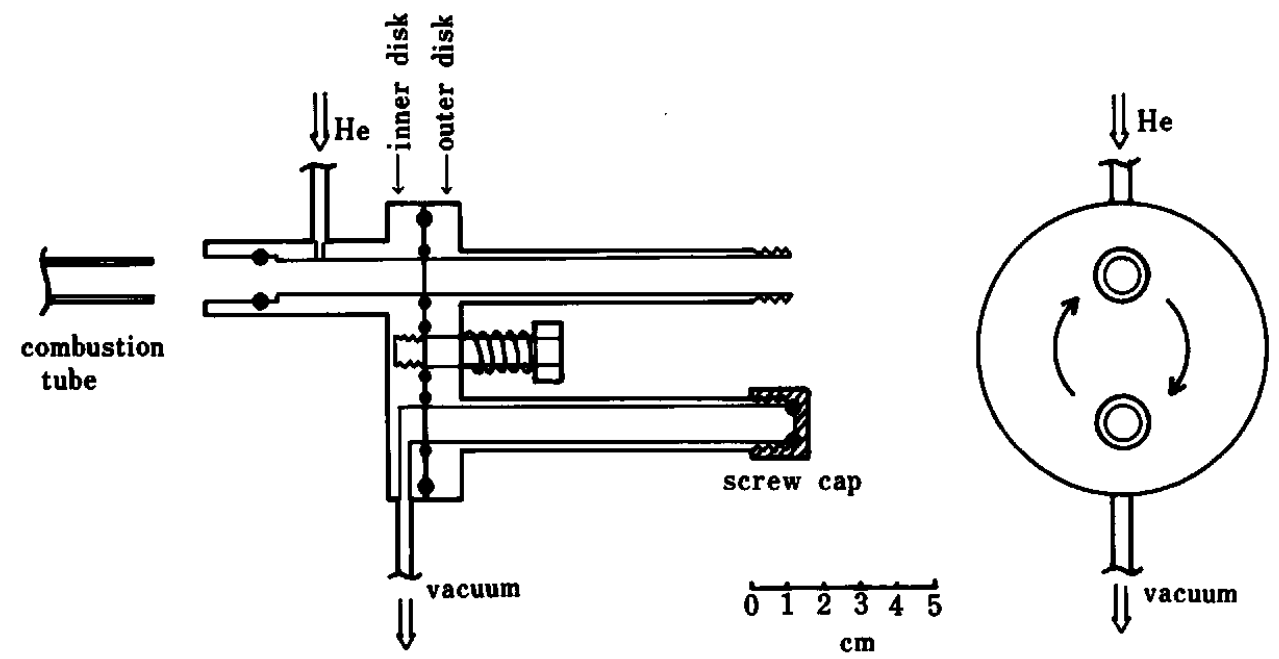

Fig. I Schematic illustration of the "revolver inlet." Filled circles indicate the sectional view of O-rings. 
without delay in order to prevent disconnection of combustion tube-revolver inlet joint which might occur otherwise because of positive helium pressure. After standing in the stream of helium for $1 \mathrm{~min}$, the sample tube is pushed further into the combustion tube with a " $L$ " shaped rod to initiate combustion. A semicircular hook is installed at one end of the sample tube which is necessary to take the tube out of the combustion tube.

\section{Results and Discussion}

We connected the revolver inlet to a combined system of an elemental analyzer and a quadrupole mass spectrometer (CN Converter and TE-360 Mass Spectrometer; Nichiden ANELVA Corp., Japan). The description of the system and its fundamental performance have been described elsewhere. ${ }^{1}$ This system has achieved the minimal nitrogen contamination of 2 ppm, in term of carrier helium, at the blank test mode. It was confirmed that the replacement of ordinary inlet with the present revolver inlet did not affect the minimized contamination level adversely.

Table 1 shows the effect of pre-evacuation using the revolver inlet. Within 5 replicate backgrownd analyses with glass fiber filters after pre-evacuation, the nitrogen and carbon content were averaged $0.17 \mu \mathrm{g}$ atom $\mathrm{N}$ and $5.05 \mu \mathrm{g}$ atom $\mathrm{C}$ with standard deviation of $0.03 \mu \mathrm{g}$ atom $\mathrm{N}$ and $0.28 \mu \mathrm{g}$ atom $\mathrm{C}$, respectively. As for the controls without pre-evacuation, the nitrogen and carbon content were averaged $0.98 \mu \mathrm{g}$ atom $\mathrm{N}$ and 5.18 $\mu \mathrm{g}$ atom $\mathrm{C}$ with standard deviation of $1.65 \mu \mathrm{g}$ atom $\mathrm{N}$ and $0.20 \mu \mathrm{g}$ atom $\mathrm{C}$, respectively. In one of the control runs, nitrogen content was $3.92 \mu \mathrm{g}$ atom $\mathrm{N}$, more than 10 times higher than the other 4 measurements, while carbon content remained at a more or less constant value. The abnormal value in $\mathbf{N}$ is obviously resulted from contamination of air trapped in the glass fiber filter. When this extreme case was excluded, the average of $\mathrm{N}$ content was turned out to be $0.25 \mu \mathrm{g}$ atom $\mathrm{N}$ with standard deviation of $0.01 \mu \mathrm{g}$ atom $\mathrm{N}$. Nevertheless, it should be noted that the average of nitrogen
Table 1 Effect of pre-evacuation on $\mathrm{N}$ and $\mathrm{C}$ determinations for glass fiber filter samples

\begin{tabular}{|c|c|c|c|}
\hline Treatment & & $\begin{array}{c}\text { Nitrogen } \\
(\mu \mathrm{g} \text { atom })\end{array}$ & $\begin{array}{c}\text { Carbon } \\
(\mu \mathrm{g} \text { atom })\end{array}$ \\
\hline Pre-evacuated & $\begin{array}{l}0.15 \\
0.17 \\
0.14 \\
0.20 \\
0.18\end{array}$ & $\begin{aligned} \bar{x} & =0.17 \\
\mathrm{sd} & =0.03\end{aligned}$ & $\begin{array}{l}4.84 \\
5.02 \quad \bar{x}=5.05 \\
4.95 \text { sd }=0.28 \\
5.53 \\
4.90\end{array}$ \\
\hline Control & $\begin{array}{l}0.25 \\
3.92 \\
0.23 \\
0.26 \\
0.25\end{array}$ & $\begin{aligned} \bar{x} & =0.98(0.25) \\
\mathrm{sd} & =1.65(0.01)\end{aligned}$ & $\begin{array}{l}5.26 \\
5.16 \quad \vec{x}=5.18 \\
4.96 \mathrm{sd}=0.20 \\
5.02 \\
5.47\end{array}$ \\
\hline
\end{tabular}

Glass fiber filters (Whatman GF/F, $25 \mathrm{~mm}$ diameter) were pre-heated at $450^{\circ} \mathrm{C}$ for $4 \mathrm{~h}$ to remove organic materials. The filter was placed in a quartz tube and treated as shown in the text. Figures in parentheses are calculated by excluding the abnormally high value (3.92). Flow rate of $\mathrm{He} ; 180 \mathrm{ml} \mathrm{min}^{-1}$.

content for control runs is significantly higher than that of pre-evacuated runs. No such difference was observed for carbon measurements.

We used quartz sample tubes in place of platinum boat. Of course this is a natural selection when a rotating disk was adopted in the revolver inlet. There is an additional advantage in this sample tube; it protects the combustion tube from accidental cracking due to adhesion of melted glass fiber filters.

The devices presented here certainly assist at least to improve the accuracy and reliability of PON determination and also to save precious samples from accidental air contamination.

\section{Reference}

1. T. Saino, Radioisotopes, 31, 561 (1982).

(Received April 20, 1987)

(Accepted April 30, 1987) 